\title{
Synthesis and Characterization of High Molecular Weight Chitosan, and Antioxidant Activity of Its Chitosan Oligosaccharide Encapsulation
}

\author{
Hari Sharan Adhikari', Aditya Garai ${ }^{2}$, Bishnu Prasad Marasini ${ }^{3}$, Rameshwar Adhikari ${ }^{4,5}$, \\ Paras Nath Yadav*5 \\ ${ }^{1}$ Department of Applied Sciences, Pashchimanchal Campus, Institute of Engineering, Tribhuvan University, \\ Pokhara, Nepal \\ ${ }^{2}$ Department of Inorganic and Physical Chemistry, Indian Institute of Science, Bangalore, India \\ ${ }^{3}$ Department of Biotechnology, National College, Tribhuvan University, Naya Bazar, Kathmandu, Nepal \\ ${ }^{4}$ Research Center for Applied Science and Technology, Tribhuvan University, Kathmandu, Nepal \\ ${ }^{5}$ Central Department of Chemistry, Tribhuvan University, Kathmandu, Nepal \\ *Corresponding E-mail: pnyadav219@gmail.com
}

(Received: September 26, 2020; Revised: January 4, 2021; \& Accepted: January 4, 2021)

\begin{abstract}
High molecular weight nanocrystalline chitosan (HMWNC) with $\mathrm{M}_{\mathrm{w}}$ of $350 \mathrm{kDa}$ and $66.92 \%$ DDA was prepared by alkaline $\mathrm{N}$-deacetylation of chitin that was abundantly obtained after demineralization and deproteinization of pulverized crab shells, and commercially available chitosan oligosaccharide (COS) with average $\mathrm{M}_{\mathrm{w}}<$ $3000 \mathrm{Da}$ and $87 \%$ DDA was encapsulated with HMWNC. The encapsulation of COS as a pharmaceutical ingredient into HMWC was hypothesized to enhance the bioavailability of COS in target cells. The HMWNC encapsulated chitosan oligosaccharide (COS-HMWNC) showed in vitro antioxidant activity on 1,1-diphenyl2-picrylhydrazyl (DPPH) radicals $\left(\mathrm{IC}_{50}=512.6 \pm 14.4 \mu \mathrm{g} / \mathrm{mL}\right.$ ) while others showed less than $50 \%$ inhibition at $1000 \mu \mathrm{g} / \mathrm{mL}$. The lower the molecular weight of chitosan, the higher was the antioxidant activity. The study showed that the encapsulation of COS molecules in HMWNC could be used as a simple and effective way of enhancing the antioxidant activity of COS.
\end{abstract}

Keywords: Antioxidant activity, chitin, chitosan oligosaccharide, high molecular weight nanocrystalline chitosan, encapsulation

\section{Introduction}

Chitin, the most abundant natural polymer after cellulose, is a homopolymer of 2-acetamido-2deoxy- $\beta$-D-glucose monomers linked through $\beta$ $(1 \rightarrow 4)$ linkages [1]. The crustacean shells as the major commercial source of chitin consist of 15$40 \%$ chitin, $20-40 \%$ protein, and $20-50 \%$ calcium carbonate and magnesium carbonate minerals in close association with minor constituents like lipids and pigments, astaxanthin, and other minerals [2]. Chitin is obtained from the exoskeleton of crustaceans after demineralization with hydrochloric acid and deproteinization with alkali. Chitosan is a partially deacetylated derivative of chitin and a copolymer of $\mathrm{N}$-acetyl and deacetyl $\alpha-(1,4)$ glucosamine $\left(\mathrm{C}_{6} \mathrm{H}_{11} \mathrm{O}_{4} \mathrm{~N}\right)$ units. Chitosan is a cationic polysaccharide due to the protonation of an amino group [3] in the backbone (figure 1) and a semi-synthetic natural product with multipurpose applications [1-4].

Chitosan is an adsorptive material [5-7], a pharmaceutical excipient [8], a permeation enhancer [9], and a hemostatic agent [10] used in the targeted delivery of drugs [11]. It shows antimicrobial [12], anticancer [13], antifungal [14], antioxidant [15] and anti-obesity [16] activities. The functional properties of chitosan such as biocompatibility and bioactivity [17] are greatly influenced by its degree of deacetylation (DDA) and molecular weight $\left(\mathrm{M}_{\mathrm{w}}\right)$ [18]. High molecular weight chitosan (HMWC) has been reported as a natural antioxidant material with a high potential for biomedical applications [19]. Nano chitosan, prepared as biocompatible polymeric nanoparticles, undergoes prolonged circulation in blood with more extravasation and passive targeting 


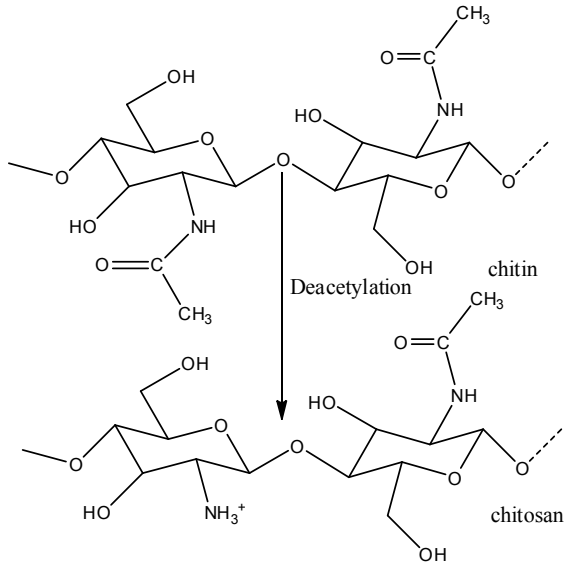

Figure 1: Deacetylation: conversion of chitin to chitosan

[20]. So, it is a suitable drug delivery candidate [2122] with a controlled delivery to the target cells in a sustained release manner by enhanced permeation and retention (EPR) effect [23]. The nanocrystalline chitosan, with a high hydrophilic and nanoparticulate creating behavior, has a great potential for the development of new complexes for regenerative medicine and tissue engineering [24].

The antioxidant defense mechanism involves scavenging and minimizing the formation of free radicals and reactive oxygen species (ROS). The systemic ineffectiveness in antioxidant defense mechanism causes oxidative stress and cellular damage [25] that leads to the progress of chronic and age-related diseases like cancer and immune system decline [26-27]. Chitosan is a sustainable natural antioxidant and its antioxidant activity is owing to the abstraction of a proton from free radicals by an amino group in the $\mathrm{C} 2$ position and hydroxy groups in the $\mathrm{C} 3$ and $\mathrm{C} 6$ positions of the pyranose ring $[13,28]$. Low molecular weight chitosan shows more scavenging of free radicals [29-30] due to its higher mobility that minimizes the possibility of both intermolecular and intramolecular hydrogen bond formation and the amino groups remain rather free to abstract proton from free radicals [29].

Chitosan has been used in the target delivery of the anticancer therapeutic agent, and nano chitosan loaded with the therapeutic agent is more stable with enhanced permeability and bioactivity [31]. Due to in vivo renal degradation, chitosan is less toxic to healthy cells [32]. Nano chitosan is biocompatible and gets internalized by the cells [33].

Encapsulation is the technique of loading a therapeutic agent inside a suitable carrier. The carrier brings about the increase in stability, bioavailability, and delivery of the therapeutic agent in a sustained release manner that prolongs its cellular uptake and presence in blood [34-35]. Cellular uptake of the encapsulated agent is essentially dependent on the charge of the Carrier [36]. The cationic carrier makes its way towards the negatively charged cell membranes [37].

The work comprised of extraction of chitin from crab shells and alkaline N- deacetylation of chitin to chitosan, preparation of high molecular weight nanocrystalline chitosan(HMWNC), physicochemical and structural characterization of HMWNC, encapsulation of COS in HMWNC and correlative study of antioxidant activity of HMWNC, COS and the encapsulated COS-HMWNC.The purpose of this work lies in bioconversion of hazardous fishery wastages of crab shells into chitosan as a value-added biomaterial of functional antioxidant activity and a controlled delivery agent of drugs.

\section{Materials and Methods}

\section{Materials}

Crab shells as fishery wastages were collected from the local market of Kathmandu, Nepal. Glacial acetic acid (Merck 99-100\%), hydrochloric acid (Merck 99\%), sodium hydroxide (Merck, 99\%), sodium acetate (Merck), ethanol (Sigma-Aldrich, 99.80\%), methanol (Sigma-Aldrich, 99.80\%), chitosan oligosaccharide (Sigma-Aldrich, 87\%) and 1,1-diphenyl-2-picrylhydrazyl (DPPH) (SigmaAldrich, 95\%) were used as received.

\section{Measurements}

The FT-IR spectrum in the powdered state was measured in the $4000-400 \mathrm{~cm}^{-1}$ regions with ATRGeXPm experimentation using BRUKER 10033610 FT-IR spectrophotometer. The solid-state ${ }^{13} \mathrm{C}-\mathrm{NMR}$ spectrum was measured using BRUKER AC-800 Delta 2 NMR spectrometer with cross-polarization at a field strength $400 \mathrm{MHz}$, scans 276, and contact time of 3.5 mins. Powder X-Ray Diffraction (XRD) measurement was performed at scanning scope of $2 \theta$ at 0 to 60 degrees with an exposure time of $400 \mathrm{~S}$ using a D8 advance BRUKER diffractometer with $\mathrm{Cu}$ target $(\lambda=0.1541 \mathrm{~nm})$ at $40 \mathrm{kV}$. The elemental analysis was performed with a Thermo Finnigan FLASH EA 112CHNS microanalyzer with carrier gas $\mathrm{He}(140 \mathrm{~mL} / \mathrm{min})$ using CHNS/ NCS column PQS SS $2 \mathrm{M} 6 \mathrm{X} 5 \mathrm{~mm}$ in the oven at $75^{\circ} \mathrm{C}$.

\section{Experiments}

\section{Synthesis of nanocrystalline chitosan}

Corresponding to the protocol of the previous works [38-39], the crab shell powder was demineralized 
and deproteinized into chitin, and crab shell chitosan was synthesized by alkaline deacetylation of chitin. Nanocrystalline chitosan was prepared with minor modification in the method given by Pighinelli et al. [24]. Crab shell chitosan (0.5 g) was dissolved in $100 \mathrm{~mL}$ of $1 \%$ acetic acid solution under stirring at $60{ }^{\circ} \mathrm{C}$ for 36 hours, and $5 \mathrm{~mL}$ of glycerol as a plasticizer was added. Sodium hydroxide solution was added under stirring till neutrality. The solution was allowed to stand at $5{ }^{\circ} \mathrm{C}$ for twenty-four hours, filtered and washed with $2 \mathrm{~L}$ of deionized water, and the residue of nanocrystalline chitosan was dried at room temperature.

\section{Determination of degree of deacetylation (DDA) and molecular weight $\left(M_{w}\right)$}

The DDA of nanocrystalline chitosan was determined with Fourier Transform- Infrared (FT-IR) spectroscopic method using the equation.

$$
D D A=100-\left(\frac{A_{1658}}{A_{8564}}\right) 100 / 1.33
$$

where $\mathrm{A}_{1658} \mathrm{~cm}^{-1}$ and $\mathrm{A}_{3364} \mathrm{~cm}^{-1}$ are absolute heights of $\mathrm{N}-\mathrm{H}$ stretch of amide $\left(\mathrm{A}_{\mathrm{NH}}\right)$ and hydroxyl absorption bands $\left(\mathrm{A}_{\mathrm{OH}}\right)$ respectively [40]. The absolute absorption heights were measured after the adoption of baselines corresponding to the amide and hydroxyl absorption peaks (figure 2).

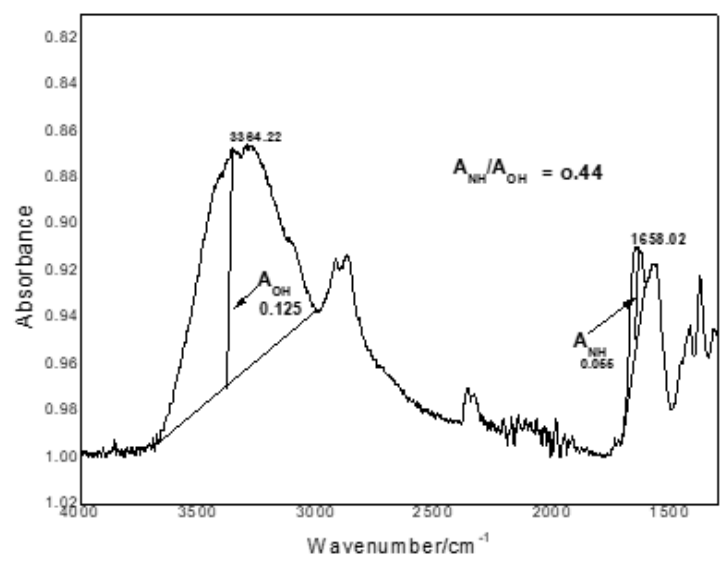

Figure 2: A portion of FT-IR spectrum of nanocrystalline chitosan with the adopted baselines for absolute heights measurement for determination of DDA

Molecular weight $\left(\mathrm{M}_{\mathrm{W}}\right)$ of nanocrystalline chitosan was determined as the viscosity average molecular weight with Mark-Houwink equation [41] through the intrinsic viscosity measurement using Ostwald's viscometer as standard [38,39].

\section{Encapsulation of chitosan oligosaccharide}

Encapsulation of COS in HMWNC was carried out with a facile synthetic modification in the method of encapsulation of oregano essential oil in chitosan nanoparticles given by Hosseini et al, [42]. The lyophilized solution of nanocrystalline chitosan (1 $\mathrm{mg}$ ) was added dropwise to $1 \mathrm{~mL}$ of chitosan oligosaccharide solution $(1 \%(\mathrm{w} / \mathrm{v})$ in $1 \%$ acetic acid solution) with constant stirring for half an hour, ultrasonicated in an ice bath for $5 \mathrm{~min}$, the opalescent solution was centrifuged for $30 \mathrm{~min}$, and the residue obtained upon filtration was dried at $60{ }^{\circ} \mathrm{C}$ for 36 hours. The supernatant solution over the centrifuged mass of chitosan encapsulation was isolated and both were stored at $4{ }^{\circ} \mathrm{C}$.

\section{Antioxidant assay}

DPPH (1,1-diphenyl-2-picrylhydrazyl) radical scavenging activity was done according to the protocol of Brand William with slight modifications [43]. Test compounds were allowed to react with stable 1, 1-diphenyl-2-picrylhydrazyl free radical for half an hour at $37^{\circ} \mathrm{C}$. After incubation, the decrease in absorption was measured at $517 \mathrm{~nm}$ using a multiplate reader (EPOCH2, microplate reader, Biotek). Now the percentage of DPPH free radical scavenging activity was calculated by using the following formula:

\section{Percentage scavenging $=(\mathrm{Ao}-\mathrm{As}) / \mathrm{Ao} \times 100$}

where, $\mathrm{Ao}=$ absorbance of the DPPH, $\mathrm{As}=$ absorbance of the DPPH free radical solution containing the sample extract. Quercetin (Himedia) was used as a standard control. All experiments were performed in triplicate. The standard graph was plotted to take the concentration on the $\mathrm{X}$-axis versus the percentage of scavenging activity on the Y-axis.

\section{Results and Discussion General}

Exoskeletons and shells of crustaceans contain chitin with minerals (mainly $\mathrm{CaCO}_{3}$ ) and protein. The appearance of brilliant white crystals of chitin after demineralization and deproteinization shows that crab shells are a major source of chitin. The crab shell chitosan was obtained as a high molecular weight chitosan with viscosity average $\mathrm{M}_{\mathrm{w}}$ of $350 \mathrm{kDa}$ and $66.92 \%$ DDA. The chitosan yield $(31.4 \%)$ was close to the reported chitosan yield of $32.2 \%$ from crab shell wastes upon $2 \mathrm{~h}$ deacetylation with $40 \%$ sodium hydroxide solution in a solid/solvent ratio of 
$1: 10(\mathrm{w} / \mathrm{v})$ [44], but higher than crab chitosan yield of $16.7 \%$ reported upon 30 min deacetylation with $45 \%$ sodium hydroxide solution in a solid/solvent ratio of $1: 10(\mathrm{w} / \mathrm{v})$ [45]. COS was commercially available as a yellow crystalline solid (figure $3 \mathrm{a}$ ) soluble in water, and HMWNC was synthesized from crab shell as an off-white solid powder (figure $3 b$ ) insoluble in water and partially soluble in dimethyl sulfoxide (DMSO).

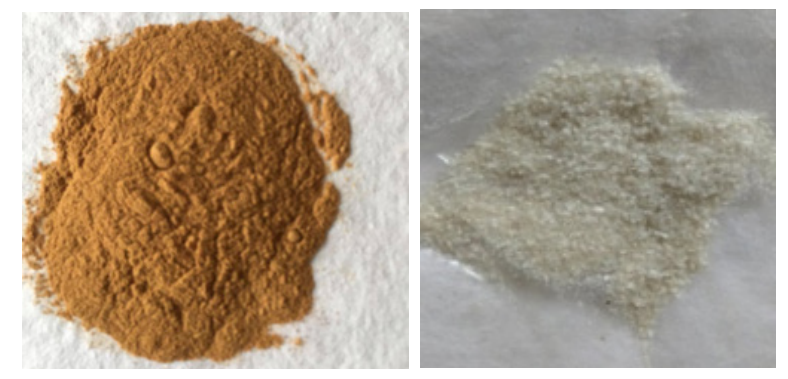

Figure 3a: Image of COS Figure 3b: Image of HMWNC

Fourier transform infrared (FT-IR) spectroscopy

The FT-IR spectroscopy in the mid spectral region of $4000-400 \mathrm{~cm}^{-1}$ provides a convenient technique for a qualitative structural elucidation and determination of DDA in chitosan [46-49]. The overall FT-IR spectrum of chitosan resembles the spectrum of cellulose with additional characteristic bands attributed to acetamido and amino group vibrations [50]. The physicochemical and biological properties of chitosan; like crystallinity, hydrophobicity, degradation, and cell response are greatly dependent on DDA [51]. The FT-IR spectroscopic method of determination of DDA is limited by the possible inaccuracy caused by interferences due to humidity and impurities in the sample [49]. Normally, the increase in DDA causes a decrease in $\mathrm{M}_{\mathrm{w}}$, which brings about the variations in physicochemical and functional properties [44]. The DDA is affected by extraction conditions viz temperature, chitin/ alkali concentration, reaction time, the particle size of chitin, and also the native source of chitin in nature [52-55].

The broadband in the FT-IR spectrum of crab shell chitosan (figure 4) corresponds tov $(\mathrm{O}-\mathrm{H})$ stretch at $3364 \mathrm{~cm}^{-1}, v(\mathrm{~N}-\mathrm{H})$ stretch at3273 $\mathrm{cm}^{-1}$, and intramolecular hydrogen bonds [56]. The weak $v$ (aliphatic C-H)symmetric stretch at $3058 \mathrm{~cm}^{-1}$ andv(aliphatic C-H) asymmetric stretch at $2873 \mathrm{~cm}^{-1}$ are characteristic peaks of polysaccharides. The presence of residual $\mathrm{N}$-acetyl groups is confirmed by a sharp characteristic $(\mathrm{C}=$ Oamide $\mathrm{I})$ stretch at 1658 $\mathrm{cm}^{-1}, v(\mathrm{C}=\mathrm{O}$ amide $\mathrm{II})$ stretch at $1560 \mathrm{~cm}^{-1}$ and the stretching vibration of $v(\mathrm{C}-\mathrm{N}$ amide III $)$ band at 1313 $\mathrm{cm}^{-1}[56]$. The broad peak at $1377 \mathrm{~cm}^{-1}$ is attributed to symmetrical deformation vibration of $\mathrm{C}-\mathrm{H}$ bonds of the methyl group. The medium absorption band at 1064 $\mathrm{cm}^{-1}$ and the sharp band at $1027 \mathrm{~cm}^{-1}$ correspond to $\mathrm{C}-\mathrm{O}$ stretching [56]. The band at $894 \mathrm{~cm}^{-1}$ corresponds to the C-O-C symmetric skeletal stretching vibration of chitosan [56-57]. The lowering of $v(\mathrm{~N}-\mathrm{H}$ amide $)$ angular bending vibration to $1560 \mathrm{~cm}^{-1}$ in crab shell chitosan is indicative of a strong hydrogen bonding in nanocrystalline form [58].

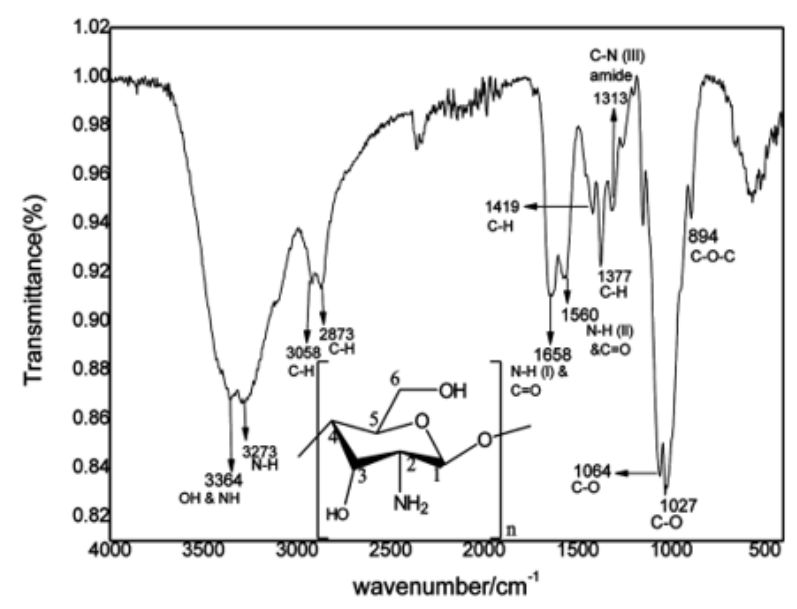

Figure 4: FT-IR spectrum of crab shell chitosan

\section{Solid-state ${ }^{13} \mathrm{C}-\mathrm{NMR}$ spectroscopy}

The structure with non-deacetylated chitin and chitosan units with a numbering of carbon atoms in the pyranose ring is shown in figure 5. Solid State ${ }^{13}$ CNMR spectrum of crab shell chitosan (figure 6), used to characterize chitosan structure, showing the chemical shift $(\delta)$ signals at $23.07 \mathrm{ppm}$ (methyl carbon of acetamido moiety), $57.50 \mathrm{ppm}\left(\mathrm{C}_{2}\right), 60.92$ $\operatorname{ppm}\left(\mathrm{C}_{6}\right), 75.70 \mathrm{ppm}\left(\mathrm{C}_{3}, \mathrm{C}_{5}\right), 83.45 \mathrm{ppm}\left(\mathrm{C}_{4}\right), 104.57$ ppm ( $\mathrm{C}_{1}$ of pyranose ring carbons), and $174.23 \mathrm{ppm}$ $(\mathrm{C}=\mathrm{O})$, was indicative of incomplete deacetylation [59]. The signals were in close agreement with the reported chitosan chemical shift $(\delta)$ signals at 24$25 \mathrm{ppm}$ (carbon atom of the methyl moieties of the acetamido groups), 57- $60 \mathrm{ppm}\left(\mathrm{C}_{2}\right), 60-63 \mathrm{ppm}\left(\mathrm{C}_{6}\right)$, 76-78 ppm $\left(\mathrm{C}_{3}, \mathrm{C}_{5}\right), 84 \mathrm{ppm}\left(\mathrm{C}_{4}\right), 106 \mathrm{ppm}\left(\mathrm{C}_{1}\right.$ of pyranose ring carbons), and $178 \mathrm{ppm}$ (attributed to $\mathrm{C}=\mathrm{O}$ indicative of incomplete deacetylation) [60-61].

\section{$\mathrm{X}$-ray diffraction analysis}

Powder X-ray diffractogram of crab shell chitosan (figure 7) showed two crystalline reflection peaks at $9.5^{\circ}$ and $19.6^{\circ}$, in close agreement with the reported peaks at $10^{\circ}$ and $20^{\circ}$ for chitosan oligosaccharide [44]. The particle size of chitosan (D) was $76 \mathrm{~nm}$, as 


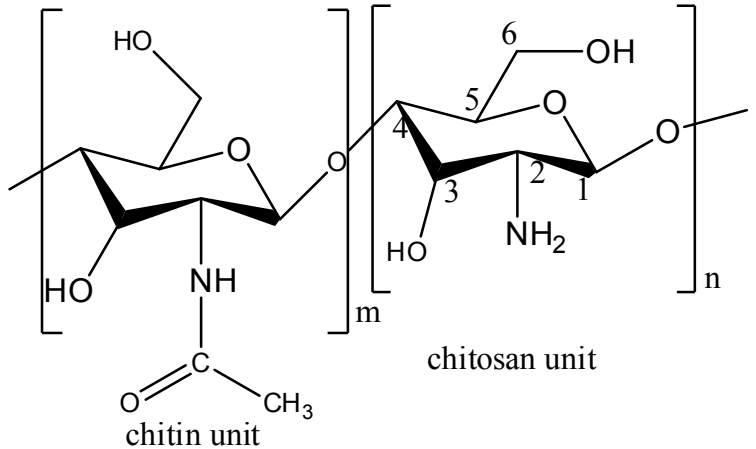

Figure 5: Structure with non-deacetylated chitin and chitosan units with numbering of carbon atoms in the pyranose ring

estimated with the help of Debye-Scherrer formula [62]. It was indicative of the aggregation of chitosan as a nano-based drug carrier system within the submicron range of $<500 \mathrm{~nm}$ particle size [63].

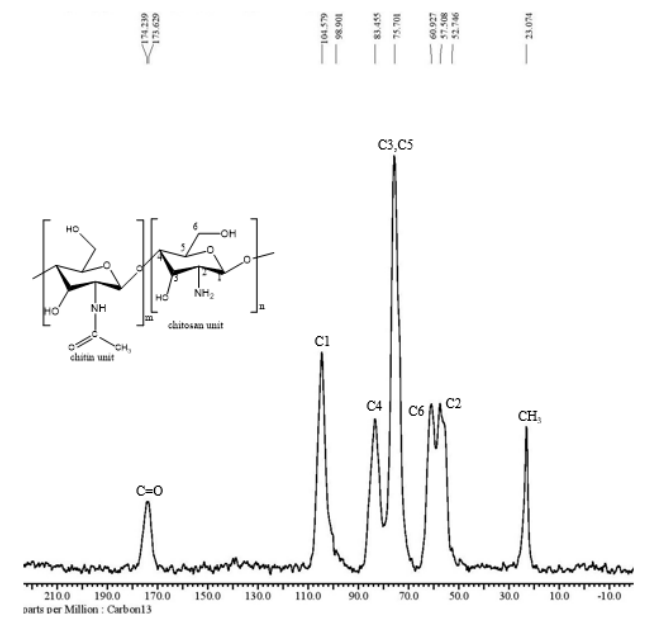

Figure 6: Solid-state ${ }^{13} \mathrm{C}-\mathrm{NMR}$ spectrum of crab shell chitosan

The degree of crystallinity was $32.84 \%$, calculated in terms of crystallinity index, with the help of formula

$$
\text { crystallinity index }=\frac{I_{c}-I_{a m}}{I_{c}} \times 100
$$

where $I_{c}$ (arbitrary unit) is maximum intensity of the crystalline peak at $\sim 20^{\circ}$ and $I_{a m}$ (arbitrary unit) is the intensity of amorphous diffraction at $12.6^{\circ}$ for chitosan chain [64]. It showed substantial order of particles in crystalline form. The crystallinity of chitosan, though partially affected by the factors like a spatial hindrance, hydrophobic force, and $\pi-\pi$ stacking [65], has been reported to be mainly dependent on DDA [66-70].

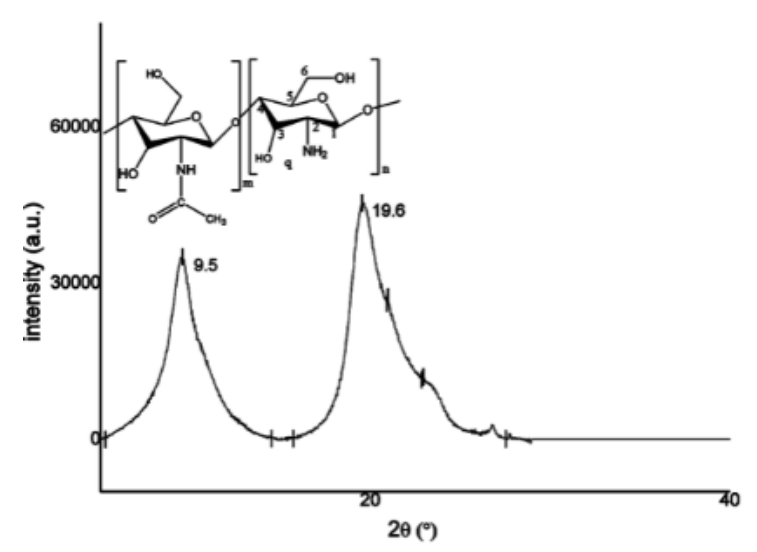

Figure 7: Powder X-ray diffractogram of crab shell chitosan

\section{Elemental microanalysis}

For chitosan with $100 \%$ DDA, corresponding to the monomer structure of unit formula weight 161.15, calculated percentages of elements are $\mathrm{C}, 52.16 ; \mathrm{H}$, $9.38 ; \mathrm{N}, 8.69$. Elemental microanalysis of crab shell chitosan (66.92\% DDA) with the percentages as C, $41.10 ; \mathrm{H}, 6.00 ; \mathrm{N}, 6.50$ were in agreement with the reported values of elemental microanalysis of chitosan oligosaccharide (87\% DDA) as C, 40.05; H, 6.41; N, 7.29 [65]. The values of the calculated $\mathrm{C} / \mathrm{N}$ ratio of chitosan with $100 \%$ deacetylation, crab shell chitosan $\left(66.92 \%\right.$ DDA and $\left.M_{w} 350 \mathrm{kDa}\right)$, and commercial chitosan oligosaccharide (87\% DDA, average $\mathrm{M}_{\mathrm{w}}<$ $3000 \mathrm{Da}$ ) are 6.00:1, 6.32:1, and 5.49:1 respectively. The alkali concentration, reaction conditions, and presence of impurities have been reported to cause the lowering of the $\mathrm{C} / \mathrm{N}$ ratio [44,71].

\section{Encapsulation of chitosan oligosaccharide}

The entrapment of lyophilized solution of crab shell chitosan viz.HMWNC in COS solution $(1 \% \mathrm{w} / \mathrm{v}$ in $1 \%$ acetic acid solution) showed a substantial loading of COS inside the high molecular weight chitosan carrier. The purpose of encapsulation lies in the formation of the ultrathin and uniform membrane to improve the bioactivity with the mass transfer of COS to the cells and aqueous phase bio adhesivity of protonated chitosan to undergo permeation through the negative cell surfaces in vitro. This process could bring about the transportation of chitosan through the epithelial surfaces to enhance its cellular bioavailability [28]. The encapsulated COS with low $\mathrm{M}_{\mathrm{w}}$ and more DDA could undergo more protonation and attraction to negatively charged cell surfaces to show higher cytotoxicity [5,72]. Conventional nanocarriers are eliminated from the systemic 
circulation by the process of phagocytosis [73]. But, high molecular weight nanocrystalline chitosan, being a permeation enhancer and biocompatible carrier could prevent phagocytosis, and increase the targeting ability of encapsulated COS. Moreover, it is a positively charged material to be easily taken up by the negatively charged membranes [36] of the target cells. The smart designing of drug carriers is crucial towards an increase in cellular uptake, interaction and bioavailability, and targeted delivery of therapeutic materials [74].

\section{Antioxidant activity}

Antioxidant profiles (figure 8) and the variation of antioxidant $\mathrm{IC}_{50}$ values (table 1) of HMWNC, COS, and COS-HMWNC showed that encapsulation was worthwhile towards the antioxidant enhancement.

Table 1: Antioxidant (DPPH) activity of HMWNC, COS,

\begin{tabular}{lcc}
\multicolumn{3}{c}{ and COS-HMWNC at $1000 \mu \mathrm{g} / \mathrm{mL}$} \\
\hline \multicolumn{1}{c}{ Sample } & $\begin{array}{c}\text { Inhibition } \\
\mathbf{( \% )}\end{array}$ & $\begin{array}{c}\mathbf{I C}_{\mathbf{5 0}} \pm \text { SEM } \\
(\boldsymbol{\mu g} / \mathbf{m L})\end{array}$ \\
\hline HMWNC & $>50$ & $\mathrm{NA}$ \\
COS & $>50$ & $\mathrm{NA}$ \\
COS- HMWNC & 65 & $512.6 \pm 14.4$ \\
Quercetin $^{\mathrm{b}}$ & 92 & $2.3 \pm 0.1$ \\
\hline
\end{tabular}

SEM $=$ Standard error of the mean at $n=3$

$\mathrm{NA}=$ not available /not tested because of less than $50 \%$ inhibition. Quercetin $^{\mathrm{b}}$ was used as a standard for radical scavenging activity

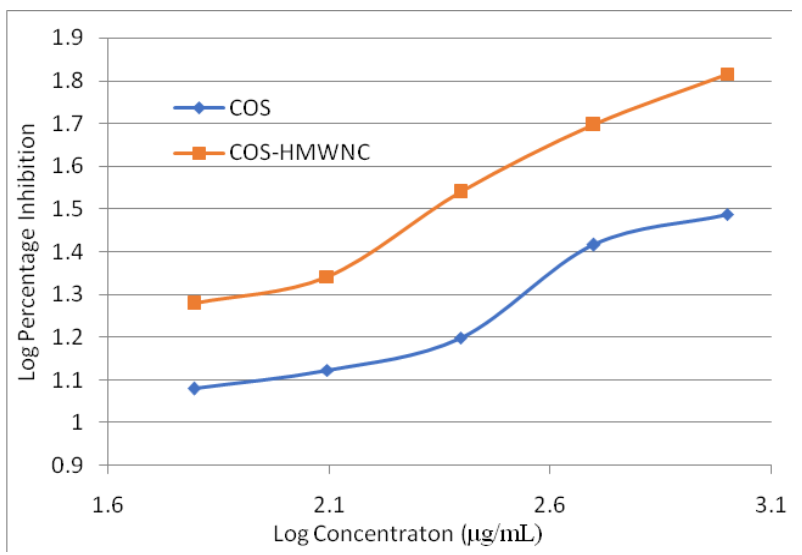

Figure 8: Antioxidant profiles of COS and COS-HMWNC

The encapsulation COS-HMWNC showed a functional antioxidant activity $\left(\mathrm{IC}_{50}=512.6 \mu \mathrm{g} /\right.$ $\mathrm{mL}$ ), in agreement with the reported $\mathrm{IC}_{50}$ of natural antioxidant chitosan at $500 \mu \mathrm{g} / \mathrm{mL}$ [75], with scavenging of free radicals (\% RSC 65), whereas COS and HMWNC showed less than 50\% RSC. The results of inhibition percentages showed that there was an increase in antioxidant activity with the increase in DDA, decrease in $\mathrm{M}_{\mathrm{w}}$ and encapsulation of COS with HMWNC as a carrier. The results are indicative of the assumption of encapsulated antioxidant material in minimum size with an increase in bioavailability and control release [76-78].

\section{Conclusions}

High molecular weight nanocrystalline chitosan was obtained as a semi-synthetic natural product from fishery wastages of crab shells. Encapsulation of commercially available chitosan oligosaccharide with this product was found significant towards the enhancement of antioxidant activity. The cellular uptake of antioxidant chitosan in vitro was found to increase with the increase in DDA and decrease in $\mathrm{M}_{\mathrm{w}}$. The antioxidant activity is attributed to cellular uptake of the compound and its action towards scavenging of free radicals inside the cell. On this basis, cellular uptake for the net antioxidant function can be generally stated to be more in the samples with more DDA and less $\mathrm{M}_{\mathrm{w}}$. The study leaves the area of further investigation on the development of sustainable and functional antioxidants with cellular specificity and controlled release of nano encapsulated chitosan.

\section{Acknowledgments}

We acknowledge Nepal Academy of Science and Technology (NAST), and Indian National Science Academy (INSA) for a research fellowship at Indian Institute of Science (IISc), Bangalore, India, and NAST in addition for Ph. D. fellowship to Hari Sharan Adhikari. We are thankful to Professor A. R. Chakravarty (IISc, Bangalore, India) and Dr. Yuba Raj Pokhrel (South Asian University, New Delhi, India) for their support to our work.

\section{References}

1. A. Percot, C. Viton and A. Domard, Optimization of chitin extraction from shrimp shells, Biomacromolecules, 2003,4, 12-18.

2. F. Khoushab and M. Yamabhai, Chitin research revisited, Marine Drugs, 2010, 8,1988-2012.

3. S. Pokhrel and P. N. Yadav, Functionalization of chitosan polymer and their applications, Journal of Macromolecular Science, Part A, 2019, 56(5), 450-475.

4. Y. N. Gavhane, A. S. Gurav and A. V. Yadav, Chitosan and its applications: a review of literature, International Journal of Pharmacy and 
Biomedical Research, 2013, 4 (1), 312-331.

5. J. K. Park, M. J. Chung, H. N. Choi, and Y.II Park, Effects of the molecular weight and the degree of deacetylation of chitosan oligosaccharides on antitumor activity, International Journal of Molecular Sciences, 2011, 12, 266-277.

6. M. Günbeyaz, A. Faraji, A. Özkul, N. Purali, and S. Şenel, Chitosan-based delivery systems for mucosal immunization against bovine herpesvirus 1 (BHV-1), European Journal of Pharmaceutical Sciences, 2010, 41, (3-4), 531-545.

7. Y. S. Wimardhani, D. F. Suniarti, H. J. Freisleben, S. I. Wanadiand M. A. Ikeda, Cytotoxic effects of chitosan against oral cancer cell lines is molecular-weight-dependent and cell-typespecific, International Journal of Oral Research, 2012, 3, e1.

8. S. D. Ray, Potential aspects of chitosan as a pharmaceutical excipient, Acta Poloniae Pharmaceutica, 2011, 68 (5), 619-622.

9. A. M. M. Sadeghi, F. A. Dorkoosh, M. R. Avadi, M. Weinhold, A. Bayat, F. Delie, R. Gurny, B. Larijani, M. Rafiee-Tehrani and H. E. Junginger, Permeation enhancer effect of chitosan and chitosan derivatives: Comparison of formulations as soluble polymers and nanoparticulate systems on insulin absorption in Caco-2 cells, European Journal of Pharmaceutics and Biopharmaceutics, 2008, 70(1), 270-278.

10. R. Gu, W. Sun, H. Zhou, Z. Meng, X. Zhu, Q. Tang, J. Dong, and G. Dou, The performance of a fly-larva shell-derived chitosan sponge as an absorbable surgical hemostatic agent, Biomaterials, 2010, 31(6), 1270-1277.

11. J. H. Park, G. Saravanakumar, K. Kimand I. C. Kwon, Targeted delivery of low molecular drugs using chitosan and its derivatives, Advanced Drug Delivery Reviews, 2010, 62(1), 28-41.

12. F. Martins, S. P. Facchi, H. D. Follmann, A. G. Pereira, A. F. Rubira and E. C. Muniz, Antimicrobial activity of chitosan derivatives containing $N$-quaternized moieties in its backbone: a review, International Journal of Molecular Sciences, 2014, 15, 20800-20832.

13. H. S. Adhikari and P. N. Yadav, Anticancer activity of chitosan, chitosan derivatives, and their mechanism of action, International Journal of Biomaterials, 2018, 2018, 1-29.

14. F. Lopez-Moya, M. F. Colom-Valiente, P. Martinez-Peinado, J. E. Martinez-Lopez, E.
Puelles, J. M. Sempere-Ortells and L. V. LopezLlorca,Carbon and nitrogen limitation increase chitosan antifungal activity in Neurospora crassa and fungal human pathogens, Fungal Biology, 2015, 119, 154-169.

15. P. J. Park, J. Y. Je and S. K. Kim, Free radical scavenging activity of chitooligosaccharides by electron spin resonance spectrometry, Journal of Agricultural and Food Chemistry, 2003, 51, 4624-4627.

16. L. K. Han, Y. Kimura and H. Okuda, Reduction in fat storage during chitin-chitosan treatment in mice fed a high-fat diet, International Journal of Obesity and Related Metabolic Disorders, 1999, 23, 174-179.

17. M. N. V. Ravi Kumar, A review of chitin and chitosan application, Reactive and Functional Polymers, 2000, 46(1), 1-27.

18. H. K. No and M. Y. Lee, Isolation of chitin from crab shell waste, Journal of the Korean Society of Food Science and Nutrition, 1995, 24 (1), 105113.

19. A. Wan, Q. Xu, Y. Sun and H. Li, Antioxidant activity of high molecular weight chitosan and $\mathrm{N}, \mathrm{O}$-quaternized chitosans, Journal of Agricultural and Food Chemistry, 2013, 61 (28), 6921-6928.

20. U. Gaur, S. K. Sahoo, T. K. De, P. C. Ghosh, A. Maitra and P. K. Ghosh, Biodistribution of fluoresceinated dextran using novel nanoparticles evading reticuloendothelial system, International Journal of Pharmaceutics, 2000, 202(1-2), 1-10.

21. E. Lee, J. Lee, I.-H. Lee, M. Yu, H. Kim, S. Y. Chae and S. Jon, Conjugated chitosan as a novel platform for oral delivery of paclitaxel, Journal of Medicinal Chemistry, 2008, 51(20), 6442-6449.

22. Y. Zhang, M. Huo, J. Zhou, D. Yu and Y. Wu, Potential of amphiphilically modified low molecular weight chitosan as a novel carrier for a hydrophobic anticancer drug: synthesis, characterization, micellization and cytotoxicity evaluation, Carbohydrate Polymers, 2009, 77(2), 231-238.

23. H. Maeda, The enhanced permeability and retention (EPR) effect in tumor vasculature: the key role of tumor-selective macromolecular drug targeting, Advances in Enzyme Regulation, 2001, 41, 189-207.

24. L. Pighinelli, M. F. Guimarães, C. M. Becker, G. Zehetmeyer, M. G. Rasia, D. S. Corrêa, R. L. 
Paz, B. G. Zannin, M. Kmiec, M. F. Tedesco, V. Reis, M. M. Silva, C. T. Feijó and C. C. Feistel, Structure and properties of nanocrystalline chitosan, Journal of Applied Biotechnology and Bioengineering, 2016, 1(1), 13-20.

25. J. E. Kinsella, E. Frankel, B. German and J. Kanner, Possible mechanisms for the protective role of antioxidants in wine and plant foods: physiological mechanisms by which flavonoids, phenolics, and other phytochemicals in wine and plant foods prevent or ameliorate some common chronic diseases are discussed, Food Technology (USA), 1993, 47(4), 85-89.

26. B. Halliwell, R. Aeschbacht, J. Loligert, and O. I. Aruoma, The characterization of antioxidants, Food and Chemical Toxicology, 1995, 33(7), 601-617.

27. M. H. Gordon, Characterization of food-emerging methods, Food Chemistry, 1996, 57(4), 587-588.

28. W. Xie, P. Xu and Q. Liu, Antioxidant activity of water-soluble chitosan derivatives, Bioorganic and Medicinal Chemistry Letters, 2001, 11(13), 1699-1701.

29. K. W. Kim and R. L. Thomas, Antioxidative activity of chitosans with varying molecular weight, Food Chemistry, 2007, 101, 308-313.

30. M.-T. Yen, J.-H. Yang and J.-L. Mau, Antioxidant properties of chitosan from crab shells, Carbohydrate Polymers, 2008, 74, 840-844.

31. P. R. Kamath and D. Sunil, Nano-chitosan particles in anticancer drug delivery: an up-to-date review, Mini Reviews in Medicinal Chemistry, 2017, 17(15), 1457-1487.

32. T. Kean and M. Thanou, Biodegradation, biodistribution and toxicity of chitosan, Advanced Drug Delivery Reviews, 2010, 62(1), 3-11.

33. M. Malatesta, S. Grecchi, E. Chiesa, B. Cisterna, M. Costanzo and C. Zancanaro, Internalized chitosan nanoparticles persist for a long time in cultured cells, European Journal of Histochemistry, 2015, 59(1), 61-65.

34. A. Kumari, S. K. Yadav, Y. B. Pakade, B. Singh and S. C. Yadav, Development of biodegradable nanoparticles for delivery of quercetin, Colloids and Surfaces B, 2010, 80, 184-192.

35. A. Kumari, S. K. Yadav and S. C. Yadav, Biodegradable polymeric nano particles-based drug delivery systems, Colloids and Surfaces B, 2010, 75, 1-18.

36. A. Verma and F. Stellacci, Effect of surface properties on nanoparticle-cell interactions, Small, 2010, 6(1), 12-21.

37. A. Muñoz Javier, O. Kreft, A. Piera Alberola, C. Kirchner, B. Zebli, A. S. Susha, E. Horn, S. Kempter, A. G. Skirtach, A. L. Rogach, J. Rädler, G. B. Sukhorukov, M. Benoit and W. J. Parak, Combined atomic force microscopy and optical microscopy measurements as a method to investigate particle uptake by cells, Small, 2006, 2(3), 394-400.

38. R. Saud, S. Pokhrel and P. N. Yadav, Synthesis, characterization and antimicrobial activity of maltol functionalized chitosan derivatives, Journal of Macromolecular Science, Part A, 2019, 56(4), 375-383.

39. M. K. Yadav, S. Pokhrel and P. N. Yadav, Novel chitosan derivatives of 2-imidazole carboxaldehyde and 2-thiophene carboxaldehyde and their antibacterial activity, Journal of Macromolecular Science, Part A, 2020, 57(10), 703-710.

40. H. Struszczyk, Microcrystalline chitosan. I. Preparation and properties of microcrystalline chitosan, Journal of Applied Polymer Science, 1987, 33(1), 177-189.

41. M. Terbojevidh and A. Cosani, Molecular weight determination of chitin and chitosan, in Chitin Handbook (R. A. A. Muzzarelli, M. G. Peter, Ed.) European Chitin Society, 1997, 87-101.

42. S. F. Hosseini, M. Zandi, M. Rezaei and F. Farahmandghavi, Two-step method for encapsulation of oregano essential oil in chitosan nanoparticles: Preparation, characterization and in vitro release study, Carbohydrate Polymers, 2013, 95(1), 50-56.

43. K. Khadayat, B. P. Marasini, H. Gautam, S. Ghaju and N. Parajuli, Evaluation of the alpha-amylase inhibitory activity of Nepalese medicinal plants used in the treatment of diabetes mellitus, Clinical Phytoscience, 2020, 6(1), article no. 34.

44. M-T. Yen, J-H. Yang and J-L. Mau, Physicochemical characterization of chitin and chitosan from crab shells, Carbohydrate Polymers, 2009, 75, 15-21.

45. H. K. No, S. H. Lee, N. Y. Park and S. P. J. Meyers, Comparison of physicochemical, binding, and antibacterial properties of chitosan prepared without and with deproteinization process, Journal of Agricultural and Food Chemistry, 2003, 51(26), 7659-7663.

46. J. Brugnerottoa, J. Lizardi, F. M. Goycoolea, W. 
Argüelles-Monal, J. Desbrières and M. Rinaudo, An infrared investigation in relation with chitin and chitosan characterization, Polymer, 2001, 42(8), 3569-3580.

47. J. Majtán, K. Bíliková, O. Markovič, J. Gróf, G. Kogan and J. Šimúth, Isolation and characterization of chitin from bumblebee (Bombus terrestris), International Journal of Biological Macromolecules, 2007, 40(3), 237241.

48. F. G. Pearson, R. H. Marchessault and C. Y. Liang, Infrared spectra of crystalline polysaccharides. V. Chitin, Journal of Polymer Science, 1960, 43(141), 101-116.

49. M. R. Kasaai, The use of various types of NMR and IR spectroscopy for structural characterization of chitin and chitosan, In Chitin, Chitosan, Oligosaccharides and Their Derivatives: Biological Activities and Applications, S. K. Kim, Ed.; CRC: Boca Raton, 2011, 149-170.

50. Y. Brummer and S. W. Cui, Detection and determination of polysaccharides in food, In Food Polysaccharides and Their Applications, $A$. M. Stephen, G. O. Phillips, P. A. Williams, Eds.; CRC: Boca Raton, 2006, 675-712.

51. M. Rinaudo, Chitin and chitosan: properties and applications, Progress in Polymer Science, 2006, 31(7), 603-632.

52. Q. Li, T. Dunn, E. W. Grandmaison and M. F. A. Goosen, Applications and properties of chitosan, Journal of Bioactive and Compatible Polymers, 1992, 7, 370-397.

53. X. F. Guo, K. Kikuchi, Y. Matahira, K. Sakai and K. Ogawa, Water-soluble chitin of low degree of deacetylation, Journal of Carbohydrate Chemistry, 2002, 21, 149-161.

54. S. V. Nemtsev, A. I. Gamzazade, S. V. Rogozhin, V. M. Bykova and V. P. Bykov, Deacetylation of chitin under homogeneous conditions, Applied Biochemistry and Microbiology, 2002, 38, 521526.

55. H. Oh., Y. J. Kim, E. J. Chang and J. Y. Kim, Antimicrobial characteristics of chitosan against food spoilage microorganisms in liquid media and mayonnaise, Bioscience, Biotechnology, and Biochemistry, 2001, 65, 2378-2383.

56. M. Fernandes Queiroz, K. Melo, D. Sabry, G. Sassaki and H. Rocha, Does the use of chitosan contribute to oxalate kidney stone formation? Marine Drugs, 2015, 13, 141-158.
57. A. Pawlak and M. Mucha, Thermogravimetric and FTIR studies of chitosan blends, Thermochimica Acta, 2003, 396, 153-166.

58. A. Rampino, M. Borgogna, P. Blasi, B. Bellichand A. Cesàro, Chitosan nanoparticles: preparation, size evolution and stability, International Journal of Pharmaceutics, 2013, 455(1-2), 219-228.

59. A. A. De Angelis, D. Capitani and V. Crescenzi,

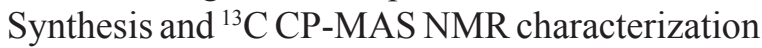
of a new chitosan-based polymeric network, Macromolecules, 1998, 31, 1595-1601.

60. D. de Britto and O. B. G. Assis, A novel method for obtaining a quaternary salt of chitosan, Carbohydrate Polymers, 2007, 69, 305-310.

61. Y. Qin, R. Xing, S. Liu, K. Li, X. Meng, R. Li, J. Cui, B. Li and P. Li, Novel thiosemicarbazone chitosan derivatives: preparation, characterization, and antifungal activity, Carbohydrate Polymers, 2012, 87, 2664-2670.

62. A. Kucukgulmez, M. Celik, Y. Yanar, D. Sen, H. Polat and A. E. Kadak, Physicochemical characterization of chitosan extracted from Metapenaeous stebbingi shells, Food Chemistry, 2011, 126, 1144-1148.

63. R. H.H. Neubert, Potentials of new nanocarriers for dermal and transdermal drug delivery, European Journal of Pharmaceutics and Biopharmaceutics, 2011, 77(1), 1-2.

64. J. Kumirska, M. Czerwicka, Z. Kaczynski, A. Bychowska, K. Brzozowski, J. Thoming and P. Stepnowski, Application of spectroscopic methods for structural analysis of chitin and chitosan, Marine Drugs, 2010, 8, 1567-1636.

65. N. Lomadze and H. J. A. Schneider, Chitosanbased chemo mechanical polymer triggered by stacking effects with aromatic effectors including amino acid derivatives, Tetrahedron, 2005, 61, 8694-8698.

66. F. Feng, Y. Liu, B. Zhao and K. Hu, Characterization of half N-acetylated chitosan powders and films, Procedia Engineering, 2012, 27, 718-732.

67. A. Di Martino, M. Sittinger and M. V. Risbud, Chitosan: a versatile biopolymer for orthopedic tissue engineering, Biomaterials, 2005, 26 (30), 5983-5990.

68. E. Khor and L. Y. Lim, Implantable applications of chitin and chitosan, Biomaterials, 2003, 24 (13), 2339-2349.

69. J. D. Bumgardner, R. Wiser, P. D. Gerard, P. Bergin, B. Chestnutt, M. Marin, V. Ramsey, S. H. 
Elder and J. A. Gilbert, Chitosan: potential use as a bioactive coating for orthopedic and craniofacial/ dental implants, Journal of Biomaterials Science, Polymer Edition, 2003, 14(5), 423-438.

70. Y. Hidaka, M. Ito, K. Mori, H. Yagasaki and A. H. Kafrawy, Histopathological and immunohistochemical studies of membranes of deacetylated chitin derivatives implanted over rat calvaria, Journal of Biomedical Materials Research, 1999, 46, 418-423.

71. C. M. Stoscheck, Quantitation of protein, in P.D. Murray (Ed.), Methods in Enzymology, Academic Press, 1990, 50-68.

72. J. Zhang, W. Xia, P. Liu, Q. Cheng, T. Tahi, W. Gu and B. Li, Chitosan modification and pharmaceutical/biomedical applications, Marine Drugs, 2010, 8(7), 1962-1987.

73. S. Storm, S. O. Belliot, T. Daemen and D. D. Lasic, Surface modification of nanoparticles to oppose uptake by the mononuclear phagocyte system, Advanced Drug Delivery Reviews, 1995, 17(1), 31-48.

74. A. Kumari, R. Singla, A. Guliani and S. K. Yadav, Nanoencapsulation for drug delivery, EXCLI Journal: Experimental and Clinical Sciences, 2014, 13, 265-286.
75. H. Rasti, K. Parivar, J. Baharara, M. Iranshahi and F. Namvarc, Chitin from the mollusc chiton: extraction, characterization and chitosan preparation, Iranian Journal of Pharmaceutical Research, 2017, 16(1), 366-379.

76. P. N. Ezhilarsi, P. Karthik, N. Chhnwal and C. Anandharamakrishnan, Nanoencapsulation techniques for food bioactive components: a review, Food and Bioprocess Technology, 2013, 6(3), 628- 647.

77. Q. Chaudhry, M. Scotter, J. Blackburn, B. Ross, A. Boxall, L. Castle, R. Aitken and R. Watkins, Applications and implications of nanotechnologies for the food sector, Food Additives and Contaminants: Part A: Chemistry, Analysis, Control, Exposure \& Risk Assessment, 2008, 25(3), 241-258.

78. M. R. Mozafari, J. Flanagan, L. Matia-Merino, A. Awati, A. Omri, Z. E. Suntres and H. Singh, Recent trends in the lipid-based nanoencapsulation of antioxidants and their role in foods, Journal of the Science of Food and Agriculture, 2006, 86, 2038-2045. 